Revue d'histoire de l'Amérique française

Ali REVUE D.HISTOIRE DE L'AMÉRIQUE FRANÇAISE

\title{
L'histoire canadienne en deuil (à la mémoire de feu Pierre-Georges Roy)
}

\section{Honorius Provost}

Volume 7, numéro 3, décembre 1953

URI : https://id.erudit.org/iderudit/301604ar

DOI : https://doi.org/10.7202/301604ar

Aller au sommaire du numéro

Éditeur(s)

Institut d'histoire de l'Amérique française

ISSN

0035-2357 (imprimé)

1492-1383 (numérique)

Découvrir la revue

Citer ce document

Provost, H. (1953). L'histoire canadienne en deuil (à la mémoire de feu Pierre-Georges Roy). Revue d'histoire de l'Amérique française, 7(3), 311-313. https://doi.org/10.7202/301604ar d'utilisation que vous pouvez consulter en ligne.

https://apropos.erudit.org/fr/usagers/politique-dutilisation/ 


\section{L'HISTOIRE CANADIENNE EN DEUIL}

\section{(à la mémoire de feu Pierre-Georges Roy)}

C'était un homme d'un genre à part, un original. Il ne vivait pas dans son siècle; du moins, son esprit travaillait dans une autre ère. On eât dit un moine réchappé du Moyen âge. Du moine il n'avait pas le froc; mais il en avait la discrète austérité et l'énergique application. Peu de paroles, un ton vif; la taille élancée mais plus souvent courbée dans le travail, sa seconde nature.

Nous l'avons vu, chercheur infatigable, piocher et fouiller le sol, où il pensait qu'il y eût d'enfouis quelques matériaux. Qu'ils fussent informes ou bien taillés, les menus galets comme les blocs solides, rien ne répugnait à sa main de collectionneur. Chaque trouvaille était étiquetée, classée d'une manière quelconque, pour pouvoir être utilisée. On eât dit, de prime abord, des amoncellements confus. Mais soudain on voyait, sous une lumière inattendue, surgir l'ordre et l'unité entre ces choses disparates, les grosses, les "petites" et même les "toutes petites". C'étaient des constructions sans ciment ni mortier qui sortaient de ses mains, la plupart du temps, avec des matériaux souvent emprisonnés dans leur gangue. Peut-être n'était-il pas né bâtisseur? Ou plutôt, il ne prenait pas ce temps, préférant se remettre à chercher et à trouver encore, dans une sorte d'enivrement et de frénésie.

Quelques ouvriers fidèles se dévouaient à son service et avaient fini par deviner ses moindres désirs. Il était devenu vieux, cassé et presque aveugle; mais il n'avait rien perdu de son ardeur et on l'admirait, on le secondait d'autant mieux qu'on le voyait en course avec le temps, ce partenaire indomptable. $\mathrm{Si}$, d'aventure, quelque jouvenceau malappris voulait lui en montrer ou se moquer de ses cheveux blancs, il savait l'écraser de son silence et le laisser ravaler lui-même son impair. Néanmoins, la généralité le tenait en vénération. Jeunes et vieux le citaient à l'envi. On a puisé et puisé 
encore dans ses travaux; on y puisera longtemps, car ils sont inépuisables.

Cet homme, dont la tombe est à peine fermée et que nous avons conduit, émus, à son dernier repos, c'était Pierre-Georges Roy. Il est décédé à Lévis, le 4 novembre, et il a été inhumé le 10, au même endroit. Il était âgé de 83 ans. Depuis si longtemps qu'on l'avait vu à l'œuvre, on eât pu le croire centenaire. Mais, c'est qu'il avait commencé très jeune. Il n'avait que vingt ans quand il fit ses premières armes, l'an 1890, en publiant deux plaquettes historiques et en commençant, à Lévis, la rédaction d'un bulletin mensuel, Le Glaneur. Ce périodique n'eut pas une longue existence. Mais son directeur ne tarda pas à lui substituer un bulletin plus substantiel et plus académique: le Bulletin des Recherches Historiques, dont le premier numéro parut en janvier 1895 et dont la publication se continue encore, sous la direction de l'Archiviste actuel de la Province, M. Antoine Roy, fils du fondateur. Nous avons là une mine inestimable, une collection évaluée aujourd'hui à prix très fort et que pas un chercheur d'histoire canadienne n'oublie de consulter. Sa réputation, d'ailleurs, a depuis longtemps franchi les frontières du pays. Déjà en 1927, un historien français en faisait l'éloge: "Tous nos lecteurs, écrivait-il, connaissent ce Bulletin des Recherches Historiques, qui, depuis 1895, constitue le précieux réceptacle où viennent s'accumuler toutes les notions d'ensemble et de détail dont la synthèse permet à l'histoire du Canada de se dessiner avec une précision que bien des vieux pays envieraient"'. $\mathrm{Si}$ nous avons un vœu à formuler, pour couronner dignement l'œuvre de PierreGeorges Roy, et nous croyons que ce vœu sera endossé par tous nos lecteurs, c'est qu'un index cumulatif du Bulletin soit publié au plus tôt par les Archives de la Province, dont l'illustre défunt fut toujours un fidèle client et, pendant un bon quart de siècle, l'âme dirigeante.

A part le Bulletin, l'œuvre de Pierre-Georges Roy fut immense. Déjà, en 1928, sa bibliographie analytique constituait un volume de 268 pages $^{2}$. Les vingt-cinq dernières années ont plus que doublé 470 .

1. J. Tramond, dans la Revue de l'Histoire des Colonies françaises, XX (1927): 1928).

2. Antoine Roy, L'Oeuvre historique de Pierre-Georges Roy, (Jouve et Cie, Paris, 
cette production et, jusqu'à 1952, l'archiviste en retraite publiait encore. Il faudra qu'on rédige sans tarder sa bio-bibliographie. Les critiques d'histoire ne jugent pas l'œuvre sans reproche. Ou trouver la perfection sur terre? On a chicané surtout l'historien sur le manque de références, un péché mortel contre la méthode scientifique. Mais il faut être juste. Pierre-Georges Roy appartient à deux générations, nous l'avons dit, et cette méthode, qui brandit l'étendard de la science, n'est pas d'introduction bien reculée chez nous. Il se trouve encore maints historiens qui n'en sont pas de très chauds partisans. Au reste, la formation de Pierre-Georges Roy a l'histoire n'a pas connu les traités de méthodologie et elle a le grand mérite d'avoir été entièrement personnelle. Après avoir ramassé des notes et des textes pendant plus de trente ans, fallait-il qu'il employât le reste de sa vie à en retrouver les sources? Mieux vaut, croyons-nous, avoir aujourd'hui ce que nous avons de lui.

Commandeur de l'Ordre de Saint-Grégoire le Grand, Chevalier de la Légion d'Honneur, lauréat de l'Académie Française, docteur de plusieurs universités, membre d'honneur de l'Institut d'Histoire de l'Amérique française, Pierre-Georges Roy emporte dans la tombe les regrets et l'estime d'une nation entière, mais il lui laisse l'héritage inappréciable de son cuvre et il demeurera comme le pionnier, le modèle des chercheurs de la petite histoire, le Georges Lenôtre du Canada, comme un journaliste l'a justement qualifié. Ayons tous une pieuse pensée pour que le Juge suprême le couronne bientôt à son tour. Opera enim illorum sequuntur illos.

Honorius Provost, ptre, membre-correspondant de l'Institut d'Histoire de l'A mérique française 